\title{
UMA PERSPECTIVA ARQUEOLÓGICA DA EDUCAÇÃO DE JOVENS E ADULTOS NO BRASIL
}

\author{
NA ARCHAEOLOGICAL PERSPECTIVE OF YOUTH AND ADULT EDUCATION IN BRAZIL
}

\author{
D https://orcid.org/0000-0002-2877-6404 Rebeca Barbosa Nascimento ${ }^{\text {A }}$ \\ (iD) https://orcid.org/0000-0003-3457-3176 Carla Luzia Borges ${ }^{B}$ \\ A Universidade Estadual de Feira de Santana (UEFS), Feira de Santana, BA, Brasil \\ ${ }^{\text {B }}$ Universidade Estadual de Feira de Santana (UEFS), Feira de Santana, BA, Brasil
}

Recebido em: 6 abr. 2020 | Aceito em: 24 ag. 2020 Correspondência: Rebeca Barbosa Nascimento (corpusrebecanascimento@gmail.com)

\section{Resumo}

Com relevantes contribuições em diversas áreas do conhecimento, Michel Foucault trouxe, em suas obras, importantes reflexões sobre os sujeitos e seus processos de constituição histórica dentro das relações estabelecidas entre poder, verdade e saber. Partindo da noção foucaultiana de sujeito, o presente trabalho configura-se como uma investigação de processos histórico-discursivos que interpelam a formação do Sujeito Estudante do Programa de Educação de Jovens a Adultos (EJA). Para tanto, foi construído um breve panorama históricodocumental sobre os movimentos de educação para jovens e adultos no Brasil, refletindo sobre a constituição do programa em sua relação com o público para o qual ele é direcionado. Com base em A Arqueologia do Saber, trazemos, portanto, de uma leitura atenta às possíveis regularidades encontradas na materialidade linguística na Proposta Curricular da Educação de Jovens e Adultos (PCEJA). A identificação das possíveis regularidades é seguida de uma caracterização das superfícies de emergência de possíveis discursos e, posteriormente, são demarcadas as possibilidades e interdições que delimitam as margens de constituição do sujeito estudante da EJA através das exterioridades.

Palavras-chave: sujeito; historicidade; educação.

\begin{abstract}
With relevant contributions in several areas of knowledge, Michel Foucault brought, in his works, important reflections on the subjects and their historical constitution processes within the relations established among power, truth and knowledge. Starting from the Foucault's concept of subject, the present work is an investigation of historical-discursive processes that question the formation of the Student of the Youth to Adult Education Program (EJA) as a subject To this end, a brief historical-documentary overview of the education movements for young people and adults in Brazil was built, reflecting on the constitution of the program in its relationship with the public to which it is directed. Based on The Archaeology of Knowledge, we bring, therefore, an attentive reading to the possible regularities found in the linguistic materiality in the Curricular Proposal for Education of Youth and Adults (PCEJA). The identification of possible regularities is followed by a characterization of the emergence surfaces of possible discourses and, later, the possibilities and interdictions that delimit the constitution edges of the student of EJA through the exteriorities are demarcated.
\end{abstract}

Keywords: subject; historicity; education. 


\section{Uma experiência escolar brasileira}

Ao ser proposta uma reflexão sobre qualquer segmento educacional no Brasil e, nesse caso, a educação voltada para jovens e adultos, é de fundamental importância compreender elementos históricos que compõem a noção de "educar" que colaboraram para que se chegasse aos modelos que hoje são práticas. Desta forma, é fundamental compreender a história atentando-se para o que Foucault chama de "história das ideias". Para o autor, "a história das ideias é, então, a disciplina dos começos e dos fins, a descrição das continuidades obscuras e dos retornos, a reconstituição dos desenvolvimentos na forma linear da história." (FOUCAULT, 2014, p.168). A história para a qual nos atentamos aqui encontra sua materialidade nas práticas e discursos que tornam possível o surgimento de um programa de educação voltado para jovens e adultos no Brasil. A construção histórica que circunda a educação de adultos no Brasil acompanha a história da educação como um todo que, por sua vez, acompanha a história dos modelos econômicos e políticos e, consequentemente, a história das relações de poder, desde as microesferas até questões ditas governamentais. Ao construírem um panorama histórico dos movimentos educacionais para indivíduos adultos no Brasil, Silva e Villa (2008) afirmam que a educação para adultos, formalmente, surge no país apenas com a chegada dos jesuítas, tendo este sistema educacional surgido, aproximadamente, no ano de 1549, com a chegada dos padres da Companhia de Jesus ao Brasil, durante o período inicial da colonização portuguesa. O caráter alfabetizador das ditas "escolas de ler e escrever" visava exclusivamente a catequização indígena, obedecendo, assim, a lógica socioeconômica colonial e todo o conjunto de crenças que tornava a catequização necessária. Esse sistema instalado pelos jesuítas acabou por expandir-se e teve sua consolidação alcançada através da construção dos Seminários. Para Silva e Villa (2008, p. 3),

\footnotetext{
do ponto de vista pedagógico, fundava-se em um sistema de ensino de cunho humanista, aristotélico-tomista, em que o aluno era convidado a comentar apenas os pontos em estudo e não a apresentar uma postura crítica, pois se partia do pressuposto de que a verdade absoluta pertencia a Deus; cabia, então, ao homem procurar a retidão em suas ações, fugindo do pecado.
}

A partir do exposto acima, é possível caracterizar a face disciplinar fundamentalmente importante dos moldes nos quais se desenvolveram as primeiras práticas educacionais para adultos. Observa-se, sob este aspecto, a criticidade como um contraponto ao que Michel Foucault (2002) chama de "vontade de verdade" (p.4). Para o autor, a vontade de verdade é um sistema de exclusão que é alicerçado e distribuído por práticas institucionais, acabando por 
produzir, sobre outros discursos, uma certa pressão, além de constrangimento. É crucial compreender que mudanças em contextos sociais e econômicos criam diferentes fontes de verdade, e assim aconteceu com os modelos escolares. O educar estava "no século XVI, o pensar era fundamentalmente religioso". Conforme já salientado anteriormente, para Foucault (2002, p. 4):

esta vontade de verdade, assim como outros sistemas de exclusão, apoia-se numa base institucional: ela é, ao mesmo tempo, reforçada e reconduzida por toda uma espessura de práticas, como a pedagogia, claro, o sistema dos livros, da edição, das bibliotecas, as sociedades de sábios outrora, os laboratórios hoje.

Assim como foi exposto, as escolas de catequese indígena, seguida pelos Seminários, mantinham sua prática pedagógica em um processo de adequação dos indivíduos ao regime de crenças do colonizador, uma vez que se objetivava a formação de indivíduos fundamentalmente cristãos e, através dessa formação, justificar práticas sociais.

O "educar" era, então, proporcionar ao aluno a aprovação social, validando comportamentos que um dado grupo de indivíduos considerava importante e coerente. Justamente por isso, era comum, por exemplo, que os donos de terra procurassem o apoio dos letrados para as práticas escravistas, o que era de interesse absoluto para a manutenção do sistema colonial.

Educar era, então, dotar o indivíduo de funcionalidade. Sobre a adequação social, Foucault (2014) trata da necessidade de questionamentos sobre o que ele chama de "soberania de uma consciência coletiva” (p.26). Para o autor, “[...] é preciso desalojar essas formas e essas forças obscuras pelas quais se tem o hábito de interligar os discursos dos homens; é preciso expulsá-las da sombra onde reinam" (FOUCAULT, 2014, p.26). A partir dessa citação, compreende-se que, para o autor, os acontecimentos sociais justificáveis, que são parte de uma gama de comportamentos sociais que caracterizam a vida coletiva como inclusas em parâmetros convencionais e, por isso, normais, precisam ter suas regularidades questionadas, trazidas à tona.

A noção de verdade foi fundamentalmente utilizada nas práticas adotadas para educação de adultos. De forma geral, o professor era o detentor do conhecimento validado socialmente, e esse conhecimento torna-se, cada vez mais, a chave para a manutenção das estruturas de poder existentes. É possível trazer à tona, ainda, o funcionamento da lógica do poder, na qual o professor caracteriza-se como elemento fundamental dentro da microesfera escolar, preparando os indivíduos para o "encaixe" institucional, instituição essa que o prepara para a adequação às macroesferas do poder. Sob essa perspectiva, Foucault (2015a) afirma ainda que "a verdade é 
deste mundo; ela é produzida nele graças a múltiplas coerções e nele produz efeitos regulamentados de poder." (p.52).

Acompanhando alterações crescentes no sistema econômico, no século XIX é possível perceber que há um novo elemento colaborador para o modelo pedagógico: o trabalho. A modificação que tomava forma nas relações trabalhistas no Brasil criou a necessidade de inserção do tema no "pensar" educacional uma vez que, no modelo escravista anterior, que tinha seus dias contados, não era preciso incluir o trabalhador no fazer pedagógico em nenhuma instância. Silva e Villa (2008, p. 2) afirmam que

o tipo de homem que cada espécie da educação visa formar é variável com a respectiva constituição social, ou seja, o homem que cada sociedade deseja formar é aquele capaz de desenvolver ao máximo as potencialidades econômicas e culturais desta forma social.

Assim, Neves (2007) afirma que, no início do século XIX, a educação primária assume o papel de converter as classes ditas subalternas ao trabalho disciplinado, por meio do Método Lancaster, instituído oficialmente por D. Pedro I, com a Lei de 15 de outubro de 1827.

O sistema monitorial, ou método Lancaster, como ficou mais conhecido no Brasil, teve o início de seu desenvolvimento na Inglaterra, no final do século XVIII e início do século XIX, momento em que o país passava por uma fase de intensa urbanização, devido ao processo acelerado de industrialização. De acordo com seus criadores, Andrew Bell e Joseph Lancaster, a proposta, pautada na meritocracia, consistia em o professor ensinar a lição a um grupo de alunos que ele julgasse mais maduros e/ou inteligentes e, após a divisão dos presentes em sala em pequenos grupos, esse grupo seleto de alunos que aprendeu a lição diretamente do professor (os monitores) era responsável por repassar os conteúdos aos demais estudantes. Assim, um mesmo professor teria condições de instruir inúmeros indivíduos de uma só vez.

Segundo Manacorda (2004), no sistema lancasteriano, cada grupo de alunos formava uma classe ou círculo, no qual cada um tinha um lugar definido pelo nível e relevância do seu saber. À medida que o aluno ia progredindo, mudava seu posicionamento na classe ou círculo. O sistema era rígido, controlado por uma disciplina severa. Manacorda salientou, ainda, que o método criado por Bell e Lancaster tinha por objetivo diminuir as despesas da instrução, abreviar o trabalho do mestre e acelerar os progressos do aluno. De forma mais clara, a proposta visava a popularização da instrução entre as classes pobres.

A principal função deste modelo de escola é "disciplinar homens indisciplinados" e, para isso, a difusão da instrução elementar às massas trabalhadoras exige a racionalização do ato pedagógico, pela rapidez de ensinar e pelo baixo custo. Entretanto, opção pelo método 
lancasteriano não significou um descaso por parte do Estado com a instrução pública, nem mesmo representou um barateamento dos custos para a difusão de escolas. O método Lancaster representava o que havia de mais moderno na prática pedagógica da época e, em contrapartida, é possível dizer que as disparidades entre as realidades sociais inglesas e brasileiras foram o alicerce para a ineficácia do sistema aqui no Brasil. Há de se salientar que, entre essas disparidades, o número expressivo de moradores da zona rural acabou por ter grande responsabilidade na falta de funcionalidade no método Lancaster: a proposta era direcionada para classes que contivessem muitos estudantes, na contramão da realidade de esvaziamento das escolas públicas urbanas.

A passagem do regime monárquico para a República refletia as modificações na composição da sociedade brasileira. Para Vanilda Paiva (1987) o progresso, que se intensificara a partir de 1870 possibilitara o surgimento de novos setores sociais e grupos econômicos ligados ao surto de industrialização que passaram a atuar na defesa dos preceitos liberais.

Outro ponto fundamental para a dificuldade da manutenção de grupos ligados aos ideais republicanos no poder é o domínio oligárquico estadual, que tinha liderança dos fazendeiros de café, caracterizando o quadro político da Primeira República, que só será alterado com a Primeira Guerra. Contudo, os movimentos operários valorizavam a educação em seus pleitos e reivindicações. Como desdobramento dessa valorização, o Decreto n. ${ }^{\circ}$ 16.782/A, de 13 de janeiro de 1925, conhecido como Lei Rocha Vaz, ou Reforma João Alves, estabeleceu a criação de escolas noturnas para adultos.

Ainda sim, por conta das questões políticas anteriormente expostas, segundo Carvalho (2010, p. 17),

somente a partir da revolução de 30 encontramos no país movimentos de educação de adultos de alguma significação. A reforma educacional de 1928 reorganizou os antigos cursos noturnos sob nova denominação: 'cursos populares noturnos'. Quanto ao conteúdo, esses cursos deveriam oferecer ensino primário em 2 anos, abrangendo noções de higiene e elementos de cultura geral.

O sentimento de nacionalismo foi fundamental o tratamento da noção de cultura nos diversos segmentos da educação. Esse nacionalismo, aliado às questões econômicas, traz, também, uma nova perspectiva sobre o significado do saber: a instrução garante prestígio social, poder.

Somente quando a instrução se converte em instrumento de identificação das classes dominantes (que a ela têm acesso) e quando se torna preciso justificar a medida de seleção é que o analfabetismo passa a ser associado à incompetência. (PAIVA, 1987, p. 83). 
O desencadeamento da Primeira Guerra Mundial teve grande responsabilidade na difusão do sentimento de nacionalismo citado anteriormente. Isso acaba por proporcionar que grupos industrial-urbanos recebam um forte estímulo de expansão e de fortalecimento, ampliando sua capacidade de luta pela hegemonia política. O nacionalismo das primeiras décadas do século XX traz consigo os ideais democráticos e republicanos, aos quais se ligam aos anseios de universalização do ensino elementar e de ampliação das oportunidades educacionais para o povo. O "entusiasmo pela educação" não sobrevive com o mesmo caráter logo após esses primeiros anos, quando foi se tornando claro para os grupos em luta no poder que, através da educação, a conquista da hegemonia política era problemática e demandava muito tempo. Assim, Moura (2007) entende que a Proclamação da República não alterou significativamente o quadro educacional, porque o modelo de educação continuou privilegiando as classes dominantes, mantendo alto o percentual da população adulta analfabeta.

Moura (2007) também afirma que a história recente da educação de adultos no Brasil pode ser dividida em três períodos: de 1946 a 1958, momento no qual foram realizadas campanhas nacionais de iniciativa oficial; de 1958 a 1964, quando houve a realização do $2^{\circ}$ Congresso Nacional de Educação de Adultos, com a participação de Paulo Freire (momento em que as proposições de Paulo Freire demarcam uma revolução conceitual para a área); pós 1964, quando o governo militar insistia em campanhas como a "Cruzada ABC" e o MOBRAL (promovendo a hegemonia da concepção instrumental de alfabetização).

\section{Formação para subjetivação do trabalhador}

Com o processo de modernização que ocorria no Brasil, aliado a uma crescente urbanização e industrialização, ampliava-se, também, a demanda pela educação como um todo, inclusive para jovens e adultos. A necessidade de mão de obra para o trabalho se desdobra na atenção para uma parcela da população analfabeta que, anteriormente, era sumariamente ignorada. Tem-se, então, uma modificação no entendimento sobre a educação no Brasil. As modificações na estrutura da sociedade brasileira explicitadas ao longo desse capítulo trouxeram a reflexão de que o analfabetismo, que antes era visto como causa da pobreza e da marginalização, era na verdade efeito da pobreza, fruto de uma lógica social não igualitária.

Essa nova forma de ver acabou por possibilitar novas abordagens teóricas sobre a noção de educação no Brasil. Entre essas novas abordagens, aquele que obteve maior destaque foi a do educador Paulo Freire. As ideias de Freire significaram um novo paradigma pedagógico, 
pois as concepções trazidas por ele expunham uma visão diferenciada sobre o analfabetismo, dando ênfase às classes populares, no sentido de entender dois tópicos bastante criticados na época: educação e sociedade.

Com a boa repercussão de sua proposta educacional, as ideias de Paulo Freire se expandiram por todo o país. A partir de então, passou a ser reconhecido nacionalmente, tanto pela educação popular em geral, quanto pela educação para adultos. O método de alfabetização utilizado por Paulo Freire caracterizava-se (e ainda se caracteriza) por possuir uma perspectiva libertadora e baseava-se, principalmente, nos conhecimentos prévios dos alunos, buscando compreender suas próprias experiências de vida, fazendo com que o indivíduo adquirisse consciência crítica, podendo compreender e questionar sua própria realidade.

\begin{abstract}
Por que não discutir com os alunos a realidade concreta a que se deva associar a disciplina cujo conteúdo se ensina, a realidade agressiva em que a violência é constante e a convivência das pessoas é muito maior com a morte do que com a vida? Por que não estabelecer uma intimidade entre os saberes curriculares fundamentais aos alunos e experiência social que eles têm como indivíduo? Por que não discutir as implicações políticas e ideológicas de um tal descaso dos dominantes pelas áreas pobres da cidade? A ética de classe embutida neste descaso? (FREIRE, 2014, p.32).
\end{abstract}

Com a crescente projeção do seu trabalho educativo, Paulo Freire foi encarregado pelo governo federal, no ano de 1963, de desenvolver o Programa Nacional de Analfabetismo e elaborar um Plano Nacional de Alfabetização. Neste contexto, a educação viria a tomar novos rumos e passaria a ser vista em outras perspectivas.

Com a implantação da ditadura civil-militar no ano de 1964, conforme trazido por Beluzo e Toniosso (2015), os grupos populares menos favorecidos perdem suas forças e o Plano Nacional de Alfabetização é interrompido, ocorrendo uma ruptura do trabalho de alfabetização realizado por Paulo Freire. Para os militares, o método por ele desenvolvido não caracterizava um ponto de interesse na nova ordem política que estava por se consolidar, uma vez que a conscientização da população acerca da dita realidade social não lhes convinha; o foco das abordagens educativas deveria ser o preparo dos indivíduos para o mercado de trabalho. Persistiram algumas iniciativas sociais, desenvolvidas frequentemente em igrejas, associações de moradores, organizações de base local e outros espaços comunitários, influenciadas pelas concepções da educação popular com intencionalidade política.

Para enfrentar o analfabetismo, o governo militar promoveu, entre 1965 e 1971, a expansão da Cruzada de Ação Básica Cristã ( $\mathrm{ABC}$ ), entidade educacional dirigida por evangélicos, surgida no Recife, para ensinar analfabetos. A Cruzada pretendia desenvolver, a partir de uma visão de integração e subordinação ao capital internacional, programas de 
alfabetização, educação continuada, comunitária e orientação profissional. Sua prática, no entanto, conforme trazido por Paiva (1987), acabou por significar a distribuição de alimentos, com a função de assegurar a atividade voluntária de professores e membros da comunidade, bem como manter elevada a frequência integral às atividades escolares. Devido às várias críticas recebidas, particularmente quanto ao recebimento de verba pública sem controle ou devida fiscalização, a Cruzada foi extinta, em 1971, pela Portaria n ${ }^{\circ}$ 237, que revogava toda a legislação anterior.

O governo federal, então, organiza o Movimento Brasileiro de Alfabetização (MOBRAL), dando início a uma forte campanha, em todo o território nacional, de alfabetização e de educação continuada para jovens e adultos. O MOBRAL, como ficou amplamente conhecido, não parou de crescer durante toda a década de 1970 e, em sua existência, obteve grande autonomia, estabelecendo sua estrutura paralela aos sistemas de ensino existentes.

Há de ser salientado o fato de o MOBRAL ter sua origem num período em que já havia um consenso mundial em torno da ineficiência das campanhas de alfabetização, o que não impediu a sua reprodução. Como alerta Machado (1999, p. 6),

A década de 70 marca (...) um novo descompasso na EJA em relação à proposta de educação como um todo. Enquanto o Ministério da Educação caminhava cada vez mais para a descentralização do Ensino Fundamental, o MOBRAL representava uma ação centralizadora de âmbito nacional desvinculada de uma coordenação direta do próprio ministério.

Em paralelo ao MOBRAL, em 1971, como desdobramento da insuficiência dos programas de educação para jovens e adultos já existentes, foi implantado o ensino supletivo através da Lei de Diretrizes e Bases da Educação Nacional (n. ${ }^{\circ}$ 5.692/71). Essa nova lei foi de extrema importância para a regulamentação da EJA, alterando a lei anterior. Pela primeira vez, uma legislação específica organizou o ensino de jovens e adultos em capítulo próprio, diferenciando-o do ensino regular básico e secundário, abordando, inclusive, a necessidade da formação de professores especificamente para ele, e trazendo avanços significativos para a EJA.

Três princípios foram fundamentais na construção do Ensino Supletivo no Brasil. O primeiro deles foi o de caracterizar o supletivo como subsistema independente do ensino regular, o que conferiria autonomia na constituição das práticas necessárias. O segundo princípio foi o de colocar o ensino supletivo voltado para o esforço do desenvolvimento nacional, integrando, pela alfabetização, a mão-de-obra marginalizada, formando força para o trabalho. O terceiro princípio, contraditório e massificante, tratava da necessidade de se pensar a metodologia e a doutrina desse segmento de ensino de forma a atender os altíssimos números 
de estudantes, característicos dessa linha de escolarização. Tem-se, então, uma quebra na lógica de uma educação condizente com a realidade na qual o estudante está inserido, já que, em um país de proporções continentais, uma metodologia unificante empobrece e descaracteriza o trabalho com elementos culturais.

Para cumprir os objetivos de formar mão de obra, repor a escolarização regular e atualizar conhecimentos, o Ensino Supletivo foi organizado, então, em quatro funções: suplência, qualificação, suprimento e aprendizagem. A Suplência e o Suprimento tinham como objetivo suprir a educação regular para adolescentes e adultos, que não a tenham concluído em tempo regular, através de cursos e exames. A aprendizagem tratava, basicamente, da formação metódica para o trabalho, o que ficou a cargo do SENAI e SENAC. A Qualificação teria, como objetivo primário, a formação de recursos humanos para o trabalho, sem a ocupação com a educação geral. O funcionamento dessas quatro modalidades deveria se realizar de forma a priorizar cursos e exames que visassem à formação e ao aperfeiçoamento para o trabalho.

É importante ressaltar, então, que muitas das modificações existentes nas práticas educacionais voltadas para jovens e adultos no Brasil partiram, essencialmente, da necessidade de adequação de uma dada parcela da população aos padrões que garantissem a manutenção da lógica econômica e social até então existente no país. Para tanto, era necessário formar esses indivíduos para o trabalho em uma dinâmica que os docilizasse e colocasse a serviço de alguém, garantindo estabilidade das dinâmicas de poder.

Oferecendo o Mobral e o Ensino Supletivo, os militares buscaram reconstruir, através da educação, sua mediação com os setores populares. Desta forma, os movimentos criados durante o regime militar, apesar de promoverem a alfabetização dos indivíduos, mantinham a criticidade longe das salas de aula.

O fato de a criticidade estar fora das salas de aula promove a restrição do acesso ao que Foucault (2015b) denomina ser "intelectual”. Para o autor, o intelectual

$$
\begin{aligned}
& \text { é alguém que ocupa uma posição específica, mas cuja especificidade está ligada às } \\
& \text { funções gerais do dispositivo de verdade em nossas sociedades. Em outras palavras, } \\
& \text { o intelectual tem uma tripla especificidade: a especificidade de sua posição de classe } \\
& \text { (pequeno burguês a serviço do capitalismo...); a especificidade de suas condições de } \\
& \text { vida e de trabalho, ligadas à sua condição de intelectual...; finalmente, a especificidade } \\
& \text { da política de verdade nas sociedades contemporâneas. (p.53) }
\end{aligned}
$$

A partir da definição de intelectual defendida, é possível reforçar que, para Michel Foucault (2015b), os instrumentos coercitivos dentro da sociedade são também geridos por uma verdade que é criada socialmente em consonância com as formas hegemônicas e que, por isso, 
acesso (ou restrição de acesso) ao conhecimento é elemento crucial no jogo de relações de poder.

Com associação entre incompetência e analfabetismo, os governos militares tiveram a necessidade de criar uma imagem favorável de seus atos políticos, criando a impressão de uma evolução social. Essa evolução social passava pela inserção das classes mais pobres em espaços escolares.

Na contramão desta "evolução", não houve investimento e nem adequação das práticas para que esses indivíduos, que agora chegavam ao ambiente escolar, pudessem ser de fato inseridos no fazer educacional. Além disso, o acesso às escolas não aconteceu uniformemente em todo território nacional. Pondo em evidência o ainda altíssimo número de analfabetos no Brasil até meados do século XX, Alves (2014) informa que, no início dos chamados "anos de chumbo" da Ditadura Militar no Brasil, a saber, a década de 70, a maior parte da população brasileira ainda vivia na zona rural, onde o índice de analfabetismo passava dos $70 \%$, sendo que este índice ainda ultrapassava os $40 \%$ para a população que habitava os grandes centros urbanos.

Silva e Villa (2008) refletem sobre como a educação para adultos colaborou na criação de números e noções fictícias sobre o ensino nacional. Para as autoras,

o conceito de educação de adultos que o regime militar consolidou é o do ensino supletivo. Com relação à formação do professor, não foi considerada também a ideia de professores especializados para este tipo de ensino e a menção explícita de uma organização escolar diferente, não marcado pelo modelo escolar regular. (p.7)

Partindo dessa reflexão, entende-se, então, que, ainda que na Lei n. ${ }^{\circ}$ 5.692/71 tenha-se abordado a formação docente e a adequação dos espaços para o trabalho com jovens e adultos, a realidade não efetivava o que o legislativo propunha, tornando a EJA uma face de diferenciação dentro do espaço de regularidades da escola.

Ponto também fundamental na reflexão sobre a história da educação para este segmento da população passa pela falta de envolvimento do Estado na criação de condições de permanência estudantil. Desde a sua criação até os dias atuais, a noção de educar adultos se desloca em processos de subjetivação de trabalhadores. Assim, pensar a questão da permanência estudantil é fundamental para validar práticas, haja vista que essa parcela da população precisa de um esforço maior para se manter em qualquer segmento de ensino. Silva e Villa (2008) mostram que outro problema refere-se à diminuição das idades mínimas para a participação neste segmento de ensino, o que acaba por criar um impacto bastante negativo na qualidade do ensino para jovens e adultos e, ao mesmo tempo, uma abordagem que não alcança 
os pressupostos teóricos necessários a um trabalho que proporcione iguais chances de inserção social aos indivíduos do ensino regular e os estudantes da EJA.

É possível dizer, então, que a realidade da EJA abarca indivíduos em "não-encaixe" institucional, aliando ao programa o discurso da exclusão, uma vez que possuir lógica de abordagem distinta não significa vetar, ao aluno desse segmento, o acesso e a construção de conhecimento.

Tratando da perspectiva docente, as Diretrizes Curriculares Nacionais para a Educação de Jovens e Adultos (BRASIL, 2015), por sua vez, destacam que a formação do professor para a EJA se dará em nível superior, estabelecendo a necessidade de formação específica diferente da educação básica, o que cabe unicamente às instituições formadoras de professores. Desta forma, mais uma vez, é possível perceber a disparidade entre a teoria e a prática no que tange a EJA, já que os centros de formação de professores, como faculdades e universidades, não disponibilizam formação específica para o trabalho com o segmento em questão nas grades curriculares dos cursos de licenciatura.

A EJA surge como forma de disciplinar o trabalhador, preparando-o para atender as necessidades de uma dada lógica econômica e social. Por isso, compreender, ainda que em pequena escala, como o discente está inserido (ou não) no processo de aprendizagem mostrase um importante ponto de reflexão para a construção do espaço "aluno EJA" e quais discursos o caracterizam.

\section{Para quais sujeitos a EJA é pensada?}

Para iniciar essa discussão, é fundamental tratar da Proposta Curricular para Educação de Jovens e Adultos, a PCEJA (BRASIL, 2002) enquanto fundamental norte documental para o trabalho com a EJA, e, por consequência, para este trabalho, uma vez que o documento objetiva, em seu conteúdo, delimitar as questões teóricas das disciplinas e caracterizar dos espaços compreendidos pelo programa, como sua trajetória histórica dos cursos de EJA.

Já na sua apresentação, a PCEJA direciona o leitor para questões fundamentais para o trabalho com o público-alvo do programa. Tendo sido escrita pela Secretaria de Ensino Fundamental, mais especificamente a COEJA (A Coordenação de Educação de Jovens e Adultos), o texto inicial já nos traz que a PCEJA objetiva oferecer norte para um trabalho "coerente com os PCN's (Parâmetros Curriculares Nacionais) do ensino fundamental" (BRASIL, 2002, p.7). Durante o breve percurso histórico construído no capítulo anterior, pôde ser percebido que os múltiplos movimentos de educação de jovens e adultos, ligados ao governo 
ou não, não obtiveram grande sucesso por possuírem um elemento comum: a tentativa de adequar as propostas de ensino de forma a suprir o tempo escolar que não fora cumprido, apresentando diretrizes de conteúdo compatíveis com o ensino regular, porém, com dois grandes diferenciais: a carga horária reduzida e o foco na inserção no mercado de trabalho. Por conta disso, a autonomia dos programas desse segmento de educação foi, e ainda é, face elementar para o estabelecimento de real eficácia no fazer educacional.

É preciso ter em mente que o público alvo da EJA possui especificidades que o diferenciam amplamente do público atingido pelo ensino padrão, e são essas especificidades que devem nortear o trabalho a ser construído. Para tanto, a compreensão das práticas discursivas filiadas ao sujeito estudante da EJA, enquanto espaço, mostra-se relevante já que pode ser percebido que o sujeito estudante do programa é primordialmente filiado às práticas discursivas sobre atividades laborais, não havendo, entretanto, o tratamento das possibilidades de continuidade da vida escolar.

De forma a facilitar o trabalho com o documento, a COEJA trouxe a PCEJA dividida em três volumes: o primeiro deles oferece ao leitor um panorama histórico sobre os processos de educação de jovens e adultos no Brasil, trazendo à tona suas dificuldades e enfrentamentos. O segundo volume traz os conteúdos a serem trabalhados nas disciplinas Língua Portuguesa, Língua Estrangeira, História e Geografia, seus objetivos e orientações didáticas. O terceiro volume segue a mesma lógica do segundo volume, mas o trabalho foca as disciplinas Matemática, Ciências Naturais, Arte e Educação Física.

Em nossa breve leitura reflexiva sobre essa proposta curricular, atentaremos nosso olhar para o ponto chave na composição do trabalho com EJA: seus princípios, também trazidos no texto de apresentação. De acordo com a PCEJA (BRASIL, 2002, p.9), esses princípios são:

\footnotetext{
- a necessidade de unir esforços entre as diferentes instâncias governamentais e da sociedade, para apoiar a escola na complexa tarefa educativa;

- o exercício de uma prática escolar comprometida com a interdependência escola/sociedade, tendo como objetivo situar os alunos como participantes da sociedade (cidadãos);

- a participação da comunidade na escola, de modo que o conhecimento aprendido resulte em maior compreensão, integração e inserção no mundo;

- a importância de que cada escola tenha clareza quanto ao seu projeto educativo, para que, de fato, possa se constituir em uma unidade com maior grau de autonomia e que todos os que dela fazem parte possam estar comprometidos em atingir as metas a que se propuseram;

- o fato de que os jovens e adultos deste país precisam construir diferentes capacidades e que a apropriação de conhecimentos socialmente elaborados é base para a construção da cidadania e de sua identidade;

- a certeza de que todos são capazes de aprender.
} 
O primeiro princípio exposto, que tange a necessidade da união de diferentes instâncias governamentais para o apoio à escola, traz à tona uma questão que há muito gera discussões e enfrentamentos: a reponsabilidade pela EJA. Essa responsabilidade não é claramente direcionada à uma instância específica, o que entrava políticas de benefício. $\mathrm{O}$ segundo princípio trata da interdependência escola/sociedade. Em sua composição, o objetivo desse princípio é situar o indivíduo estudante como participantes da sociedade. O efeito de sentido trazido por esse enunciado pode remeter a ideia de um aluno sendo informado sobre a realidade que o cerca, sem poder de questionamento ou reflexão. Situar os alunos na sociedade pode levar a noção de encaixe, o que não necessariamente pressupõe inclusão. O terceiro princípio referese à participação da comunidade na escola, questão que já se configura como ponto de debate dentro do próprio ensino regular.

Sob a lógica desses parágrafos, o conhecimento aprendido deve resultar na compreensão, integração e inserção no mundo. $\mathrm{O}$ enunciado em questão nos leva a reflexão de que aluno deve aprender para compreender o mundo ao seu redor, e não o questionar, já que, de forma subsequente, essa compreensão leva a integração e inserção. A regularidade encontrada nos enunciados contidos nos segundo e terceiro princípios caracteriza uma prática discursiva que reduz, ao sujeito estudante da EJA, o lugar de replicador.

De forma subsequente, o quarto princípio trazido na PCEJA propõe que cada escola tenha clareza do seu projeto educativo. Segundo essa proposta, essa clareza possibilitaria a constituição de maior autonomia nesse espaço. A questão da autonomia foi muitas vezes trazida como importante ponto de base para a constituição da educação de jovens e adultos. Entretanto, foi visto que, na prática, essa autonomia não se configura como realmente efetiva, já que as propostas para EJA acabam sendo criadas de forma consoante ao ensino regular, apesar das claras diferenças entre os públicos alcançados pelos dois segmentos. Além disso, a dita autonomia na prática escolar acaba, por vezes, significando a falta de fiscalização do trabalho de fato desenvolvido para esse programa, o que deturpa os procedimentos propostos na PCEJA.

No quinto princípio, trazido na proposta curricular, acabamos encontrando a palavra que melhor sintetizou o trabalho com a educação de jovens e adultos: apropriação. Seguindo a lógica desse princípio, deve-se ter em mente o fato de que os jovens e adultos precisam construir diferentes capacidades e que "a apropriação de conhecimentos socialmente elaborados é a base para a construção da cidadania e de sua identidade" (BRASIL, 2002, p.9). O questionamento que salta aos olhos do leitor é sobre os conhecimentos "socialmente elaborados" referidos na constituição desse princípio e, indo além disso, qual foi a sociedade que o elaborou, o que pode 
trazer a ideia de que o indivíduo estudante da EJA não faz parte do processo de elaboração de conhecimento. Corroborando essa noção, o uso do vocábulo apropriação fecha a reflexão sobre o papel do sujeito estudante da EJA suposto pela Proposta Curricular que norteia o trabalho dentro do programa; não cabe ao sujeito estudante da educação de jovens e adultos o poder de refletir sobre os conhecimentos trazidos dentro do espaço escolar. Em suma, o estudante deve compreender e apropriar-se, pois só assim sua inserção social se torna viável.

Nesse recorte, é possível dizer o princípio aqui analisado ignora a realidade dos indivíduos presentes em sala, uma vez que interliga a apropriação de saberes institucionalmente validados à construção de subjetividade.

\section{Quem é o sujeito aluno da EJA?}

A noção de enunciado é muito importante para pensar o que caracteriza o processo de subjetivação dos estudantes EJA, partindo de uma proposta metodológica de base foucaultiana, uma vez que se faz necessário demarcar os espaços sociais que possibilitam o aparecimento ou interdição de um dado discurso, assim como debruçar-se sobre as práticas institucionalizadas que atuam na constituição e delimitação dos discursos, dos quais o enunciado se apresenta como unidade elementar. Em A Arqueologia do Saber, Foucault (2014) refere-se aos enunciados como um conjunto de signos em função enunciativa, e é essa função enunciativa que interessa no processo de descrição arqueológica. Gregolin (2004, p.26) esclarece a noção de função enunciativa:

O que torna uma frase, uma proposição, um ato de linguagem, um enunciado é justamente... o fato de ele ser produzido por um sujeito, em um lugar institucional, determinado por regras socio-históricas que definem e possibilitam que ele seja enunciado.

A abordagem do conceito de enunciado mostra-se importante porque o enunciado, enquanto átomo do discurso, não pode ser reduzido aos elementos linguísticos. Contudo, no trabalho construímos, é necessário salientar os textos enquanto prática: estando inseridos em materialidade documental, interpelados pela materialidade histórica dos princípios do programa, é possível dizer que os enunciados analisados, em sua textualidade, encontram-se em pleno exercício de função enunciativa.

Assim, segundo Foucault (2014), há de se levar em consideração as condições que proporcionam a aparição de uma dada prática discursiva. Foucault define as práticas como a racionalidade ou a regularidade que organiza o que os homens fazem, tendo um caráter 
sistemático e recorrente girando em torno do poder e do saber. Sobre o conceito de prática discursiva, Foucault esclarece que

não podemos confundi-la com a operação expressiva pela qual um indivíduo formula uma ideia, um desejo, uma imagem; nem com a atividade racional que pode ser acionada em um sistema de inferência; nem com a 'competência' de um indivíduo falante, quando constrói frases gramaticais; é um conjunto de regras anônimas, históricas, sempre determinadas no tempo e o espaço, que definiram, em uma dada época e para uma determinada área social, econômica, geográfica ou linguística, as condições de exercício da função enunciativa. (FOUCAULT, 2014, p.143-144).

Dentro dessa perspectiva, o método de análise arqueológico nos leva à construção dos entornos da possibilidade de aparição dos enunciados; são linhas importantes de serem demarcadas, uma vez que mostram o modo como, para Foucault, a análise dos enunciados tem mais a ver com a descrição da função de existência histórica, seus efeitos de sentido e desdobramentos nas relações de poder, que com a descrição de seus caracteres linguísticos ou semiológicos. Em suma, os enunciados podem ou não assumir função enunciativa, condicionada a práticas discursivas, dentro de sua historicidade.

É nessa historicidade que se possibilita a caracterização das regularidades que demarcam as formações discursivas (FD). Sobre o que seria a formação discursiva, Foucault nos traz, em A Arqueologia do Saber, a seguinte reflexão:

No caso em que se puder descrever, entre um certo número de enunciados, semelhante sistema de dispersão, e no caso em que entre os objetos, os tipos de enunciação, os conceitos, as escolhas temáticas, se puder definir uma regularidade (uma ordem, correlações, posições, funcionamentos, transformações), diremos, pode convenção, que se trata de uma formação discursiva. (FOUCAULT, 2014, p.47).

Ainda buscando compreender o pensamento foucaultiano, faz-se importante trazer, também, a noção de "Arqueologia do Saber". Esse conceito foi abordado pelo pensador na entrevista de 1972, intitulada Da Arqueologia à Dinastia. Nela, o autor expõe: "o que chamo de "arqueologia do saber" é, em termos, o balizamento e a descrição dos tipos de discurso" (FOUCAULT, 2015b, p.47). As condições históricas são, ainda, extremamente importantes para a compreensão dos discursos, uma vez que

não se pode falar de qualquer coisa em qualquer época; não é fácil dizer alguma coisa nova; não basta abrir os olhos, prestar atenção, ou tomar consciência para que novos objetos logo se iluminem e, na superfície do solo, lancem sua primeira claridade. (FOUCAULT, 2014, p.54).

Sintetizando os conceitos expostos acima, entende-se, então, que há de se considerar a existência de um enunciado a partir de sua função enunciativa (qual sujeito o enunciou, onde e 
quando), sendo esta determinada e condicionada dentro de uma dada prática discursiva. A partir de então, identificam-se as regularidades que caracterizam uma dada formação discursiva.

Tendo construído essa reflexão, faz-se importante compreender que o direcionamento do segmento de ensino nomeado Educação de Jovens e Adultos possui demarcações específicas quanto ao seu público alvo, tendo em vista que este público não estaria em situação adequada para o ensino dito regular. Além disso, não é incomum encontrar estudantes repetentes ou oriundos de situação de evasão escolar em anos anteriores, muitos desses alunos já trabalhadores. De forma mais clara, o programa em questão é pensado para atender a um público que, em sua face mais elementar, já não está enquadrado na escola.

A EJA representa, então, a própria desordem (des)qualificada. Ao tempo que é desqualificada por estar fora de uma ordem escolar, ela se qualifica por estar legitimada num espaço educativo, regida por princípios específicos e cumprindo uma função esperada: a de formar determinado grupo de indivíduos para determinado tipo de trabalho.

Sob essa lógica, é admissível caracterizar, então, a proposta do programa como possível superfície de emergência de discursos que visam à ordenação, a adequação do sujeito estudante e, como consequência, sua interdição e/para inserção social.

Oferecer ensino de qualidade em todas as instituições que trabalham com educação de jovens e adultos é uma necessidade urgente: merecem respeito as pessoas que buscam a escola para completar a trajetória escolar, muitas vezes motivadas pela demanda crescente de um nível de escolaridade cada vez maior, a fim de que tenham aumentadas as chances de inserção no mercado de trabalho, na cultura e na própria sociedade. (BRASIL, 2002, p.117).

Ora, qual a relação clara, então, que é possível estabelecer entre os enunciados encontrados nos corpus e o sujeito propriamente dito, tendo esclarecida a ideia de enunciado enquanto elementar e a função enunciativa como os entornos de sua existência, haja vista que o trabalho aqui proposto tem seu olhar voltado para esse sujeito estudante da EJA? Essa relação é trazida à tona a partir do momento em que é salientado que o sujeito do enunciado não pode ser reduzido a elementos gramaticais e que, quando tratamos do sujeito do enunciado, não estamos tratando propriamente de indivíduos.

Gregolin (2004) traz, ainda, que o fundamental nessa relação é determinar qual lugar é possível (e essencial) ocupar um indivíduo para que ele possa ser sujeito de um dado enunciado uma vez que, conforme exposto por Milanez e Santos (2010, p.45), "antes de fonte dos discursos, o sujeito é apenas uma posição ocupada por aquele que enuncia algo". O sujeito seria, assim, um composto, uma determinada identidade produzida em condições e por relações específicas; o sujeito é um enunciado social. A análise de base arqueológica pressupõe o 
questionamento dos enunciados a partir do ponto que se leva em consideração os entornos de seu aparecimento e, no caso da análise aqui proposta, os enunciados encontrados nos princípios da PCEJA nos conduzem para os discursos que atuam na delimitação do sujeito estudante da Educação de Jovens e Adultos, haja vista que o documento em questão é direcionada para esse sujeito pressuposto e, por isso, torna-se possível afirmar que sua composição, aliada ao que foi trazido da historicidade das políticas para esse público atua no redirecionamento dos indivíduos alunos do programa para esse lugar.

\section{Conclusões da construção de um sujeito}

Pensar a EJA enquanto segmento nos remete ao processo de "Democratização do Ensino" e como esse acabou levando ao aumento do número de escolas de forma substancial. Ao mesmo tempo, esse aumento no número de escolas trouxe consigo o aumento no contingente de estudantes presentes nas instituições. Percebe-se, então, uma incoerência estrutural nessa dinâmica das escolas: o modelo escolar vigente, regular, fora construído direcionando seus interesses à classe média letrada, o que instalava uma situação caótica nos modelos de ensino com a chegada dos iletrados, filhos de uma classe trabalhadora recém-chegada à escola.

Dentro dessa realidade, a Educação de Jovens e Adultos foi sendo estruturada para recepcionar os excluídos dentro dos excluídos. Fora da idade supostamente correta para as salas de aula, o indivíduo estudante da EJA acabou por ser encaixado em uma lógica escolar que pressupõe, para esse sujeito, espaços outros, diferentes aos do aluno dito regular.

Durante a breve abordagem histórica e documental trazida nesse trabalho, pôde ser visto que esse segmento de educação surge e vai sendo estruturado aliado às demandas sociais e, de forma mais enfática, econômicas de cada momento histórico: ao programa, fica a responsabilidade de habilitar os indivíduos à funcionalidade social, mais especificamente, ao mercado de trabalho. Nesse processo de habilitar, entretanto, é possível visualizar que as possibilidades desse sujeito estudante são determinadas, marcadas pelas interdições geradas nas regularidades encontradas na história e em suas materialidades e, dentro dessa lógica, ratificase que o programa de Educação de Jovens e Adultos (EJA) caracteriza-se como espaço de diferenciação e, porque não dizer, exclusão, dentro da instituição escola já que, para o sujeito do programa, as práticas construídas sutilmente hierarquizam espaços e possibilidades, interditando, para esse sujeito, a qualificação de seus saberes.

Os discursos que circundam a formação do sujeito estudante da EJA, aquele que caracteriza uma evidente regularidade refere-se à interdição à continuidade da escolarização. 
A história nos mostrou que o segmento educacional em questão foi desenvolvido de forma a constituir mão de obra necessária à manutenção do sistema econômico, sistema esse que foi sofrendo modificações de forma a adequar-se às demandas sociais. Essas demandas trouxeram-nos a uma realidade na qual a não-escolarização representa o que existe de feio e indesejável na sociedade e, nessa perspectiva, quanto maior o número de indivíduos escolarizados, maior a sensação de seguridade social. No entanto, há de se atentar o olhar para o fato de que, no caso da EJA, a escolarização, contraditoriamente nomeada de "educação", atende à produção de um sujeito ao qual não é suposto o alto nível de instrução. Essa interdição é percebida na ausência de qualquer abordagem sobre universidade na Proposta Curricular do programa. Ao sujeito estudante da Educação de Jovens e Adultos, é reservado o espaço da "nãointelectualidade", representada por trabalhos que gozam de menos prestígio social.

A reflexão desenvolvida leva-nos, então, à construção de sujeito ao qual é interditado o poder de questionar; a este sujeito, caberia a apropriação e replicação, entendidas como condições de sustentação de seu encaixe institucional e, porque não dizer, demarcação do espaço do corpo discente do programa dentro da própria sociedade. É necessário salientar, entretanto, a possiblidade de resistência para esses sujeitos em seu processo de formação: na compreensão da historicidade e da estrutura escolar, os sujeitos forjam novas condições de possibilidade para si, possibilidades essas que sustentam a relevância de trabalhos que atuam na emergência dessas vozes historicamente interditadas.

\section{Referências}

ALVES, Pedro Ernesto Ribeiro. O movimento Diretas Já e o papel dos jornais "o grito da Terra" e "Feira Hoje" no município de Feira de Santana. 2014. 61f. Trabalho de conclusão de curso (Bacharelado em Ciências Sociais) - Universidade Federal do Recôncavo Baiano, Cachoeira.

BAHIA. Política de EJA da Rede Estadual. Salvador: Secretaria de Educação do Estado da Bahia, 2009.

BELUZO, Maira Ferreira; TONIOSSO, José Pedro. O Mobral e a alfabetização de adultos: considerações históricas. In: Cadernos de Educação: Ensino e Sociedade, v. 2, n. 1, p: 196209, 2015.

BRASIL. Diretrizes curriculares nacionais para a Educação de Jovens e Adultos. Disponível em: <www.inep.gov.br>. Acesso em: 29 nov. 2015. 
BRASIL. Ministério da Educação. Secretaria de Educação Continuada, Alfabetização e Diversidade. Documento Nacional Preparatório à VI Conferência Internacional de Educação de Adultos (VI CONFINTEA) / Ministério da Educação (MEC) - Brasília: MEC; Goiânia: FUNAPE/UFG.

BRASIL. Lei de Diretrizes e Bases da Educação Nacional. Disponível em: < http://portal.mec.gov.br/arquivos/pdf/ldb.pdf > Acesso em: 14 jul. 2015a.

BRASIL. Proposta Curricular para a educação de jovens e adultos: segundo segmento do ensino fundamental: $5^{\mathrm{a}}$ a $8^{\mathrm{a}}$ série. Brasília: Ministério da Educação/ Secretaria de Educação Fundamental, 2002.

CARVALHO, Marlene. Primeiras letras - Educação de jovens e adultos em espaços populares. São Paulo: Ática, 2010.

FOUCAULT, Michel. A arqueologia do saber. Tradução de Luiz Felipe Baeta Neves. 8. ed. Rio de Janeiro: Forense Universitária, 2014.

FOUCAULT, Michel. Estratégia, Poder-Saber. 3.ed. Organização de Manoel Barros da Motta. Rio de Janeiro: Forense Universitária, 2015a (Coleção Ditos e Escritos IV).

FOUCAULT, Michel. Microfísica do poder. 2.ed. Rio de Janeiro: Paz e Terra, 2015b

FOUCAULT, Michel. A ordem do discurso. São Paulo: Loyola, 2002.

MACHADO, Maria Margarida. Política educacional para jovens e adultos: lições da história. São Paulo, 1999.

MANACORDA, M. História da Educação: da antiguidade aos nossos dias. 11 ed. São Paulo: Cortez, 2004.

MOURA, M da G. C. Educação de jovens e adultos no Piauí - 1971 a 2002. Disponível em: <www.sbhe.org.br>. Acesso em: 1 set. 2007.

MILANEZ, Nilton; SANTOS, Janaína de Jesus. Geometria discursiva entre Nietzsche e Foucault. IN: MILANEZ, Nílton; GASPAR, Nádea Regina. (orgs.) A (des)ordem do discurso. São Paulo: Contexto, 2010.

NEVES, F. M. O Método Lancasteriano e o ensino da ordem e da disciplina para os soldados do império brasileiro. Mimeog. 2007.

PAIVA, Vanilda. Educação popular e educação de adultos. 4. ed. São Paulo: Edições Loyola, 1987.

SILVA, C. P. da; VILLA, V. Teoria e prática da educação de jovens e adultos no Brasil e a formação dos professores. Disponível em:

<www.pucpr.br/eventos/educere/educere2008/anais/pdf/545_207>. Acesso em: 25 nov. 2008. 